\title{
Predictors of In-Hospital Mortality in Patients Admitted with Acute Myocardial Infarction in a Developing Country
}

\author{
Omar Chehab ${ }^{\mathrm{a}, \mathrm{b}}$, Abdul Salam Qannus ${ }^{\mathrm{a}, \mathrm{b}}$, Mahmoud Eldirani ${ }^{\mathrm{a}}$, Hussein Hassan ${ }^{\mathrm{a}}$, \\ Hani Tamima ${ }^{\text {a }}$ Habib A. Dakik ${ }^{\text {a, c }}$
}

\begin{abstract}
Background: Limited data are available on the predictors of mortality in patients hospitalized with acute myocardial infarction (AMI) in developing countries. In this study, we analyze the predictors for in-hospital mortality in patients hospitalized with AMI (ST segment elevation myocardial infarction (STEMI) and non-ST-elevation myocardial infarction (NSTEMI)) in a large tertiary referral university hospital in Lebanon.
\end{abstract}

Methods: This was a retrospective study of 503 patients admitted to the American University of Beirut Medical Center with AMI (228 with STEMI and 275 with NSTEMI).

Results: The in-hospital mortality rate was $7.8 \%$. The multivariate predictors of mortality in the overall population were similar to what has been reported in large registries in the USA and Europe. They included older age $(>65$ years $)(\mathrm{OR}=2.99,95 \% \mathrm{CI}=1.22-7.36, \mathrm{P}$ $=0.02)$, systolic blood pressure $<100 \mathrm{~mm} \mathrm{Hg}(\mathrm{OR}=2.75,95 \% \mathrm{CI}$ $=1.12-6.76, \mathrm{P}=0.03)$, history of stroke $(\mathrm{OR}=4.28,95 \% \mathrm{CI}=1.29$ - $14.17, \mathrm{P}=0.02)$, history of coronary artery bypass graft $(\mathrm{CABG})$ $(\mathrm{OR}=2.68,95 \% \mathrm{CI}=1.15-6.23, \mathrm{P}=0.02)$, heart failure $(\mathrm{OR}=3.92$, $\mathrm{CI}=1.62-9.49, \mathrm{P}=0.002)$ and ejection fraction $(\mathrm{EF})<35 \%(\mathrm{OR}=$ $2.32,95 \% \mathrm{CI}=1.05-5.14, \mathrm{P}=0.04)$. In a separate analysis of STEMI and NSTEMI patients, age, heart failure and a low EF continued to be multivariate predictors of mortality in both subgroups. In addition, prior stroke was an added predictor in STEMI patients, and prior CABG was an added predictor in NSTEMI.

Conclusion: Predictors of in-hospital mortality in patients hospitalized with AMI in a tertiary referral university hospital in the Middle East are similar to what has been reported in large registries in the USA and Europe.

Keywords: Myocardial infarction; Hospital mortality; Developing

Manuscript submitted August 10, 2018, accepted August 27, 2018

${ }^{a}$ Department of Internal Medicine, American University of Beirut Medical Center, Beirut, Lebanon

${ }^{b}$ Drs Omar Chehab and Abdul Salam Qannus had equal contribution to this study.

${ }^{\mathrm{c} C}$ Corresponding Author: Habib A. Dakik, Department of Internal Medicin, American University of Beirut Medical Center, Beirut, Lebanon.

Email: hd01@aub.edu.lb

doi: https://doi.org/10.14740/cr772w countries; ST elevation myocardial infarction; non-ST elevation myocardial infarction

\section{Introduction}

Acute myocardial infarction (AMI), including both ST segment elevation myocardial infarction (STEMI) and non-STelevation myocardial infarction (NSTEMI), represent a major cause of morbidity and mortality worldwide [1]. Although healthcare systems have made marked improvements in developing systematic methods for early recognition and management of patients with AMI, short-term in-hospital mortality remains high.

Several studies in the USA and Europe have investigated the predictors of in-hospital mortality post-AMI [2-7]. Several variables were identified related to the clinical characteristics of the patients and their comorbidities [3, 4, 7-10]. Similar studies on AMI patients in developing countries are scarce [11], and little is known about the management and mortality rates of such patients in these countries [12]. The aim of our study is to investigate the predictors for in-hospital mortality in patients admitted with AMI at the American University of Beirut Medical Center (AUBMC), a tertiary referral university hospital in Lebanon.

\section{Patients and Methods}

This is a substudy of a large retrospective study that enrolled all patients $(1,025)$ admitted with an acute coronary syndrome to AUBMC between January 1, 2002 and December 30, 2005 [13]. In this substudy, we focus on the subgroup of patients who had AMI (either STEMI or NSTEMI) with the appropriate clinical presentation, electrocardiograph (ECG) findings and rise in cardiac biomarkers as per published guidelines [14]. AUBMC is the largest tertiary referral university hospital in Lebanon with a 20 bed coronary care unit, two active cardiac catheterization laboratories and a busy cardiothoracic surgery program.

The clinical characteristics of patients as well as the occurrence of in-hospital death were collected retrospectively from medical chart review. Statistical analysis was performed using the Statistical Package for Social Sciences software (SPSS ver- 
sion 15). Continuous variables are presented as mean $\pm \mathrm{SD}$ and categorical variables are presented as frequencies and percentages. Comparison of baseline characteristics and in-hospital interventions and outcomes among the three groups of patients (All AMI, STEMI and NSTEMI) in Tables 1 and 2, were done using the analysis of variance (ANOVA) test (for continuous variables) or the $\chi^{2}$ homogeneity test (for categorical variables). Logistic regression analysis was performed to determine the predictors of in-hospital mortality among the three groups.

\section{Results}

The clinical characteristics of the study population as well as the medications and interventions utilized are shown in Tables 1 and 2. The study included a total of 503 AMI patients $(45 \%$ STEMI and 55\% NSTEMI). The overall in-hospital mortality was $7.8 \%$ (7.9\% in STEMI and 7.6\% in NSTEMI).

In the total group of AMI patients, those who died were older (mean age of $77 \pm 12$ years versus $63 \pm 13$ years, $\mathrm{P}<$ $0.0001)$, had a higher percentage of women (39\% versus $22 \%$, $\mathrm{P}=0.02)$ and a higher prevalence of prior coronary artery disease (CAD) $(56 \%$ versus $36 \%, \mathrm{P}=0.01)$, congestive heart failure $(\mathrm{CHF})(31 \%$ versus $9 \%, \mathrm{P}<0.0001)$, chronic kidney disease $(\mathrm{CKD})(28 \%$ versus $9 \%, \mathrm{P}<0.001)$ and stroke $(18 \%$ versus $3 \%, \mathrm{P}<0.001)$. They also had a lower mean systolic blood pressure on admission (120 $\pm 27 \mathrm{~mm} \mathrm{Hg}$ versus $136 \pm$ $29 \mathrm{~mm} \mathrm{Hg}, \mathrm{P}=0.001)$, hemoglobin level (12 $\pm 2 \mathrm{~g} / \mathrm{dL}$ versus $13 \pm 2 \mathrm{~g} / \mathrm{dL}, \mathrm{P}=0.001)$ and ejection fraction $(28 \pm 11 \%$ versus $48 \pm 14 \%, \mathrm{P}<0.0001)$. In addition, they had a higher prevalence of decompensated heart failure on admission $(36 \%$ versus $9 \%, \mathrm{P}<0.0001)$ and cardiogenic shock $(10 \%$ versus $2 \%, \mathrm{P}=0.01)$. In terms of medical therapy, patients who died were more likely to be on inotropic support with dopamine or dobutamine, but they were less likely to receive other medications such as aspirin (80\% versus $93 \%, \mathrm{P}=0.006)$, clopidogrel (49\% versus $82 \%, \mathrm{P}<0.0001)$, statins $(13 \%$ versus $61 \%, \mathrm{P}<0.0001)$ and beta blockers $(28 \%$ versus $62 \%, \mathrm{P}<$ $0.0001)$. Coronary angioplasty was less commonly utilized in those patients as well $(12 \%$ versus $38 \%, \mathrm{P}=0.003)$, but the rates of coronary artery bypass graft $(\mathrm{CABG})$ were similar. When separate analyses were done for STEMI and NSTEMI patients (also shown in Tables 1 and 2), similar patterns were noted in both groups.

Using multivariate logistic regression analysis (Table 3), the significant multivariate predictors of mortality in the overall AMI population were: older age ( $>65$ years), lower systolic blood pressure and CHF on admission, prior history of stroke or CABG and a lower ejection fraction. Age, CHF on admission and a lower EF continued to be multivariate predictors for both STEMI and NSTEMI subgroups. In addition, prior stroke was an added predictor in STEMI patients, and prior CABG was an added predictor in NSTEMI patients.

\section{Discussion}

This is one of the few studies that analyzed the predictors of in-hospital mortality in a relatively large number of patients hospitalized with AMI in a tertiary referral university hospital in a developing country. The identified predictors were similar to those reported from large AMI registries in the USA and Europe. Older age has been a consistent predictor of mortality in multiple AMI studies. In a 20-year population study, Goldberg et al showed that the risk of death increased proportionally with age with patients older than 85 years of age having more than 10 times the mortality risk compared to patients ageing between 55 and 64 years [15]. Similar findings were reported by Rosengren et al from the EuroHeart survey [16]. Our findings are consistent with these studies where age was a significant predictor of in-hospital mortality in the overall AMI population as well as in each of the STEMI and NSTEMI subgroups. Multiple reasons have been proposed to explain this increased risk. Elderly people are expected to have more extensive coronary disease and yet they are less likely to receive the same intensive management as younger patients regarding revascularization procedures and anti-ischemic therapy [16-19]. Both the CRUSADE and EuroHeart studies showed that the revascularization rate decreased progressively as the patient's age increased [18].

Heart failure and low ejection fraction $(<35 \%)$ were also shown to be consistent predictors of mortality in our overall AMI population as well as in both STEMI and NSTEMI subgroups. The ESC guidelines have underscored the importance of these two variables in the management of patients with AMI in view of their association with high risk [20]. Killip class was determined to be an important predictor of mortality for more than 50 years now [21]. The importance of heart failure on admission was further illustrated in a large nationwide USA study (NRMI-2) that enrolled around 170,000 patients with AMI in which it was associated with a five-fold increase in mortality [22]. Similarly, the GRACE registry showed that heart failure on admission was associated with four-fold increase in mortality [2].

Prior history of stroke was an important predictor of mortality in our study as well. This goes hand in hand with various studies that found that patients who survive an initial stroke are more prone to die in the future from cardiac events such as myocardial infarction $[23,24]$. The CRUSADE registry that enrolled around 43,000 patients with AMI showed that stroke was a strong predictor of long-term morality [25].

Patients with prior history of CABG have also been shown in multiple studies to be at increased risk of death following an AMI $[26,27]$, similar to what we found in our study. Finally, we found that the lack of utilization of clopidogrel was a significant predictor of mortality. The protective effect of clopidogrel has now been established in multiple randomized trials in a wide spectrum of patients with acute coronary syndromes [28-30]. However, because of the retrospective nature of our study, it is difficult to determine whether the lack of prescribing clopidogrel leads to the increased mortality or it was simply a marker of a higher risk population.

\section{Strengths and limitations}

This is one of the few studies that analyzes the predictors of 


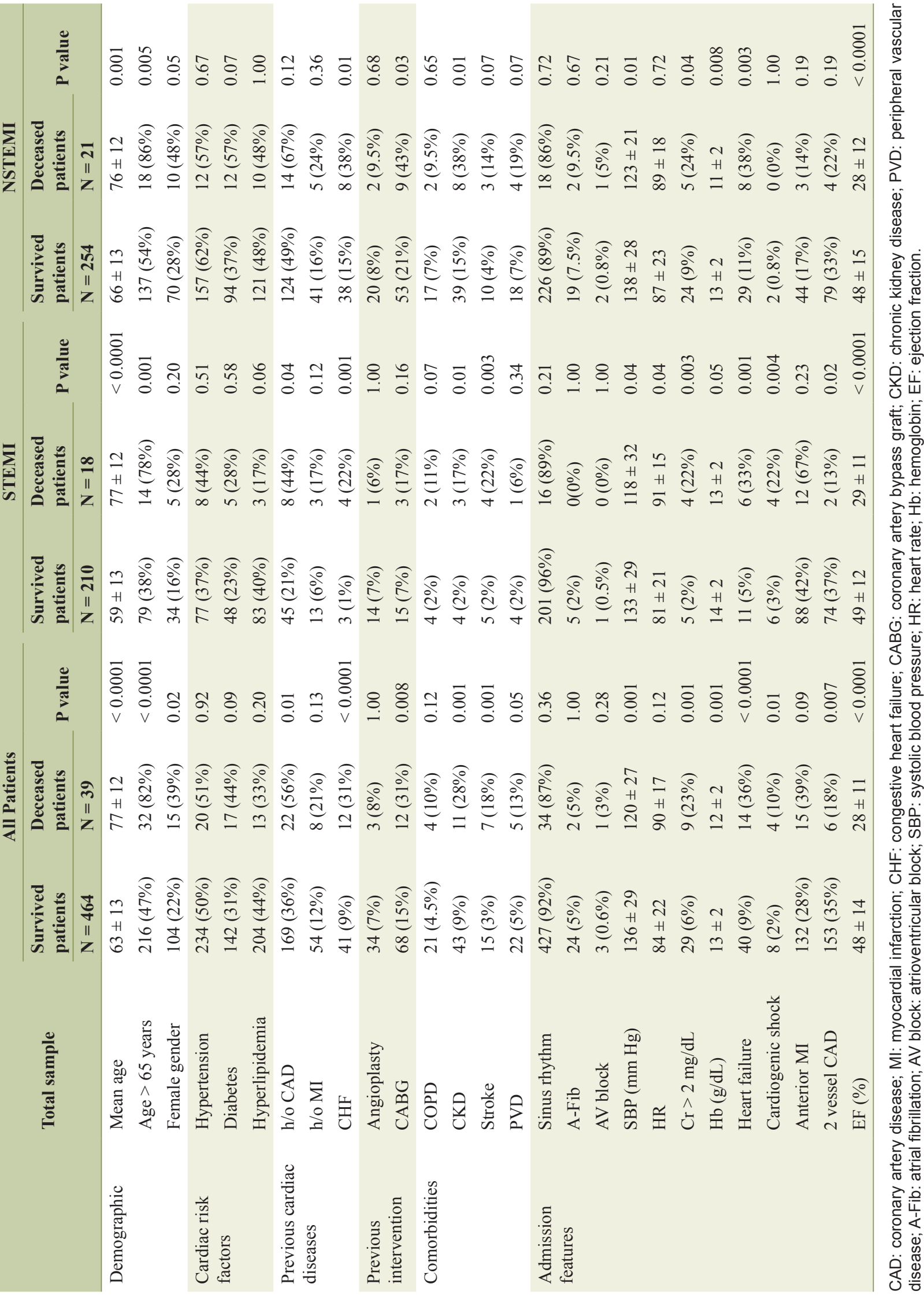




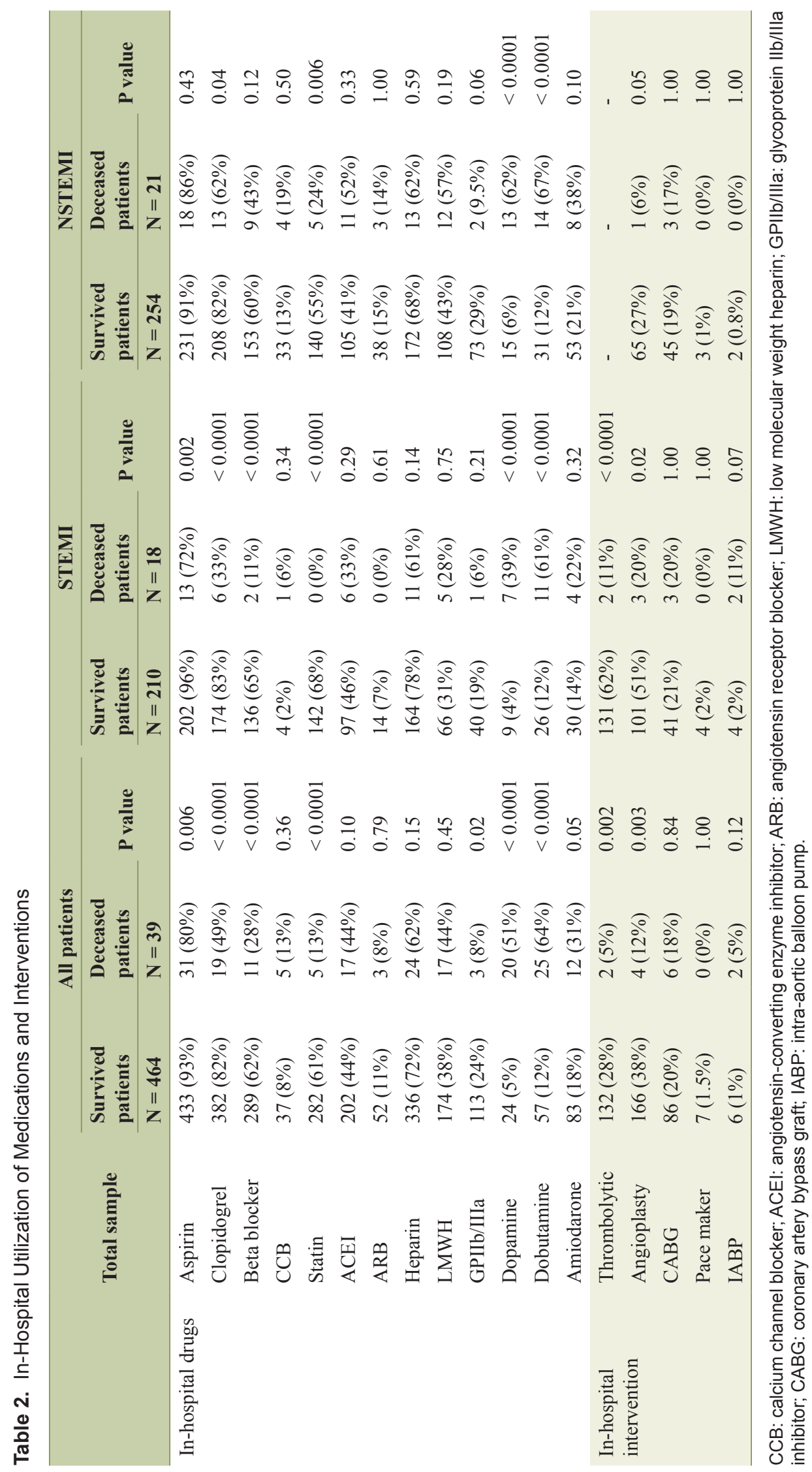


Table 3. Multivariate Predictors of Mortality

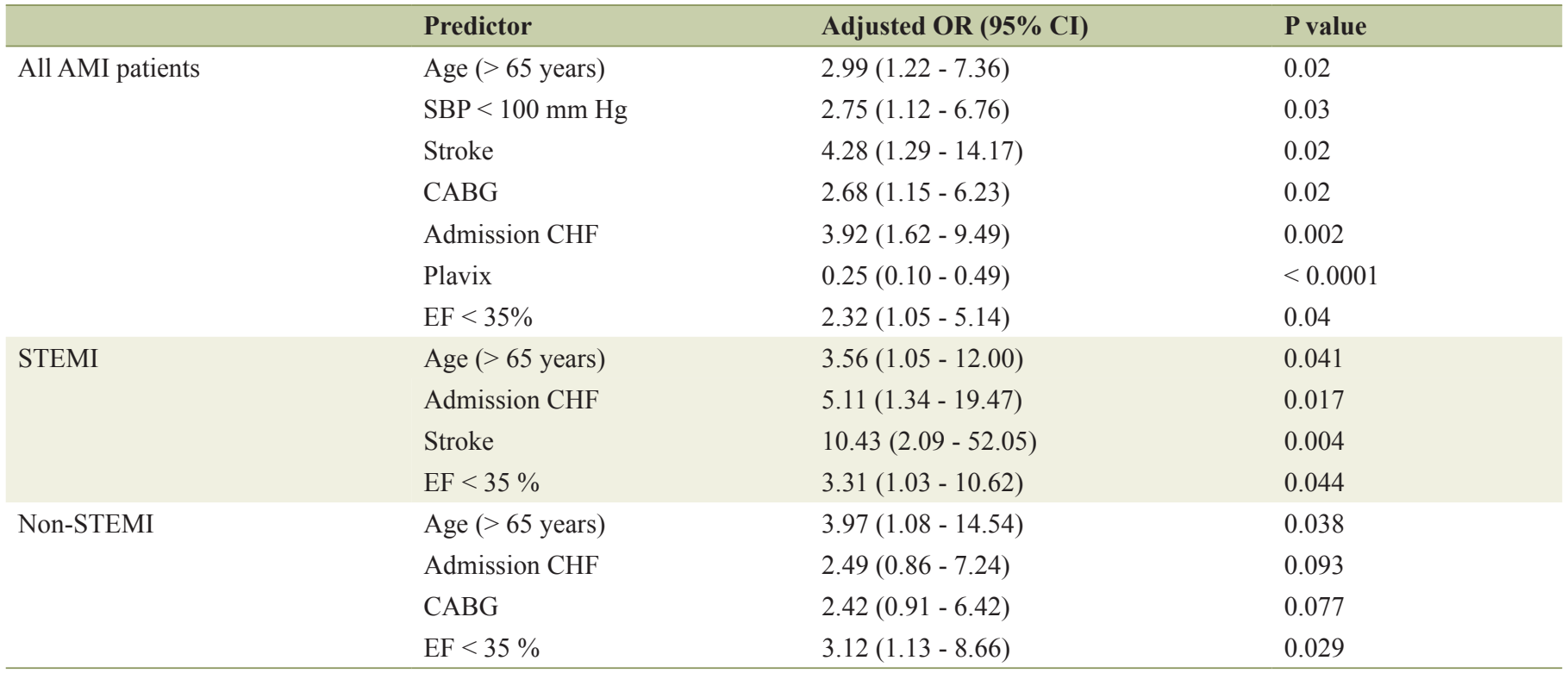

CHF: congestive heart failure; CABG: coronary artery bypass graft; EF: ejection fraction; SBP: systolic blood pressure.

in-hospital mortality among patients with AMI in a developing country. In view of the scarcity of similar data from these countries, our report fills an important gap of knowledge in the global perspective on AMI. The important limitations of the study are that it is a single-center initiative and it is retrospective. This limits the extrapolation of findings to other countries. We hope that more resources will be invested in these countries to perform multicenter prospective surveys that can more accurately characterize the population of AMI patients.

\section{Conclusions}

This is one of the few studies that analyzes the predictors of in-hospital mortality among patients hospitalized with AMI in a large tertiary referral university hospital in the Middle East. The identified predictors are similar to what has been reported in large registries in the USA and Europe. These included older age, heart failure, prior stroke or $\mathrm{CABG}$, and a lower ejection fraction. Large multicenter prospective studies are needed to further characterize the population of AMI patients in these countries.

\section{Conflict of Interest}

The authors report no relationships that could be construed as a conflict of interest.

\section{Author Contributions}

HAD conceived the study and contributed to the design of the study. OMC, ASQ, MED and HH drafted the manuscript and contributed with the data collection. HT contributed with the data analysis and the revision of the final manuscript. All authors read and approved the final version of the manuscript.

\section{Financial Support}

This research did not receive any specific grant from funding agencies in the public, commercial or not-for-profit sectors.

\section{References}

1. Lloyd-Jones D, Adams R, Carnethon M, De Simone G, Ferguson TB, Flegal K, Ford E, et al. Heart disease and stroke statistics - 2009 update: a report from the American Heart Association Statistics Committee and Stroke Statistics Subcommittee. Circulation. 2009;119(3):e21-181.

2. Steg PG, Dabbous OH, Feldman LJ, Cohen-Solal A, Aumont MC, Lopez-Sendon J, Budaj A, et al. Determinants and prognostic impact of heart failure complicating acute coronary syndromes: observations from the Global Registry of Acute Coronary Events (GRACE). Circulation. 2004;109(4):494-499.

3. Timoteo AT, Toste A, Ramos R, Oliveira JA, Ferreira ML, Ferreira RC. Admission heart rate as a predictor of mortality in patients with acute coronary syndromes. Acute Card Care. 2011;13(4):205-210.

4. Fox KA, Eagle KA, Gore JM, Steg PG, Anderson FA, Grace, Investigators G. The global registry of acute coronary events, 1999 to 2009-GRACE. Heart. 2010;96(14):1095-1101.

5. Park DW, Kim YH, Yun SC, Ahn JM, Lee JY, Kim WJ, Kang SJ, et al. Frequency, causes, predictors, and clinical 
significance of peri-procedural myocardial infarction following percutaneous coronary intervention. Eur Heart J. 2013;34(22):1662-1669.

6. Ponniah JP, Shamsul AS, Adam BM. Predictors of mortality in patients with Acute Coronary Syndrome (ACS) undergoing Percutaneous Coronary Intervention (PCI): Insights from National Cardiovascular Disease Database (NCVD), Malaysia. Med J Malaysia. 2012;67(6):601605.

7. Constantinides SS, Gieowarsingh S, Halim M, Been M, Shiu MF. Predictors of mortality in patients with acute coronary syndrome undergoing percutaneous coronary intervention. Heart. 2003;89(10):1245-1246.

8. Antman EM, Tanasijevic MJ, Thompson B, Schactman M, McCabe CH, Cannon CP, Fischer GA, et al. Cardiacspecific troponin I levels to predict the risk of mortality in patients with acute coronary syndromes. N Engl J Med. 1996;335(18):1342-1349.

9. Maeder MT. Comorbidities in patients with acute coronary syndrome: rare and negligible in trials but common and crucial in the real world. Heart. 2014;100(4):268270.

10. Francisco AR, Sousa M, Amador P, Goncalves S, Mendes L, Seixo F, Santos JF, et al. Chronic medical comorbidities in patients with acute coronary syndrome. Rev Port Cardiol. 2010;29(1):7-21.

11. Zubaid M, Rashed WA, Almahmeed W, Al-Lawati J, Sulaiman K, Al-Motarreb A, Amin H, et al. Management and outcomes of Middle Eastern patients admitted with acute coronary syndromes in the Gulf Registry of Acute Coronary Events (Gulf RACE). Acta Cardiol. 2009;64(4):439446.

12. El-Menyar A, Zubaid M, Shehab A, Bulbanat B, Albustani N, Alenezi F, Al-Motarreb A, et al. Prevalence and impact of cardiovascular risk factors among patients presenting with acute coronary syndrome in the middle East. Clin Cardiol. 2011;34(1):51-58.

13. Abdallah M, Karrowni W, Shamseddeen W, Itani S, Kobeissi L, Ghazzal Z, Alam S, et al. Acute coronary syndromes: clinical characteristics, management, and outcomes at the American University of Beirut Medical Center, 2002-2005. Clin Cardiol. 2010;33(1):E6-E13.

14. Alpert JS, Thygesen K, Antman E, Bassand JP. Myocardial infarction redefined - a consensus document of The Joint European Society of Cardiology/American College of Cardiology Committee for the redefinition of myocardial infarction. J Am Coll Cardiol. 2000;36(3):959-969.

15. Goldberg RJ, McCormick D, Gurwitz JH, Yarzebski J, Lessard D, Gore JM. Age-related trends in short- and long-term survival after acute myocardial infarction: a 20-year population-based perspective (1975-1995). Am J Cardiol. 1998;82(11):1311-1317.

16. Rosengren A, Wallentin L, Simoons M, Gitt AK, Behar S, Battler A, Hasdai D. Age, clinical presentation, and outcome of acute coronary syndromes in the Euroheart acute coronary syndrome survey. Eur Heart J. 2006;27(7):789795.

17. Stone PH, Thompson B, Anderson HV, Kronenberg MW, Gibson RS, Rogers WJ, Diver DJ, et al. Influence of race, sex, and age on management of unstable angina and nonQ-wave myocardial infarction: The TIMI III registry. JAMA. 1996;275(14):1104-1112.

18. Skolnick AH, Alexander KP, Chen AY, Roe MT, Pollack CV, Jr., Ohman EM, Rumsfeld JS, et al. Characteristics, management, and outcomes of 5,557 patients age $>$ or $=90$ years with acute coronary syndromes: results from the CRUSADE Initiative. J Am Coll Cardiol. 2007;49(17):1790-1797.

19. Malkin CJ, Prakash R, Chew DP. The impact of increased age on outcome from a strategy of early invasive management and revascularisation in patients with acute coronary syndromes: retrospective analysis study from the ACACIA registry. BMJ Open. 2012;2(1):e000540.

20. Task Force on the management of ST-segment elevation acute myocardial infarction of the European Society of Cardiology (ESC), Steg PG, James SK, Atar D, Badano LP, Blömstrom-Lundqvist C, Borger MA, et al. ESC Guidelines for the management of acute myocardial infarction in patients presenting with ST-segment elevation. Eur Heart J. 2012;33(20):2569-2619.

21. Killip T, 3rd, Kimball JT. Treatment of myocardial infarction in a coronary care unit. A two year experience with 250 patients. Am J Cardiol. 1967;20(4):457-464.

22. Becker RC, Burns M, Gore JM, Spencer FA, Ball SP, French W, Lambrew C, et al. Early assessment and inhospital management of patients with acute myocardial infarction at increased risk for adverse outcomes: a nationwide perspective of current clinical practice. The National Registry of Myocardial Infarction (NRMI-2) Participants. Am Heart J. 1998;135(5 Pt 1):786-796.

23. Vernino S, Brown RD, Jr., Sejvar JJ, Sicks JD, Petty GW, O'Fallon WM. Cause-specific mortality after first cerebral infarction: a population-based study. Stroke. 2003;34(8):1828-1832.

24. Dhamoon MS, Tai W, Boden-Albala B, Rundek T, Paik MC, Sacco RL, Elkind MS. Risk of myocardial infarction or vascular death after first ischemic stroke: the Northern Manhattan Study. Stroke. 2007;38(6):1752-1758.

25. Roe MT, Chen AY, Thomas L, Wang TY, Alexander KP, Hammill BG, Gibler WB, et al. Predicting long-term mortality in older patients after non-ST-segment elevation myocardial infarction: the CRUSADE long-term mortality model and risk score. Am Heart J. 2011;162(5):875883 e871.

26. Jenkins CD, Stanton BA, Savageau JA, Denlinger P, Klein MD. Coronary artery bypass surgery. Physical, psychological, social, and economic outcomes six months later. JAMA. 1983;250(6):782-788.

27. Geissler B, Aggestrup S. [Qualitative assessment of pain relief and functional improvement after coronary bypass surgery. A questionnaire survey among 527 patients]. Ugeskr Laeger. 2002;164(11):1506-1510.

28. Chen ZM, Jiang LX, Chen YP, Xie JX, Pan HC, Peto R, Collins R, et al. Addition of clopidogrel to aspirin in 45,852 patients with acute myocardial infarction: randomised placebo-controlled trial. Lancet. 2005;366(9497):16071621.

29. Sabatine MS, Cannon CP, Gibson CM, Lopez-Sendon JL, 
Montalescot G, Theroux P, Claeys MJ, et al. Addition of clopidogrel to aspirin and fibrinolytic therapy for myocardial infarction with ST-segment elevation. N Engl J Med. 2005;352(12):1179-1189.

30. Yusuf S, Zhao F, Mehta SR, Chrolavicius S, Tognoni G,
Fox KK, Clopidogrel in Unstable Angina to Prevent Recurrent Events Trial I. Effects of clopidogrel in addition to aspirin in patients with acute coronary syndromes without ST-segment elevation. N Engl J Med. 2001;345(7):494502. 